\title{
Studies on the Effects of Environmental Pollution on ACSR Conductors
}

\begin{abstract}
DANIEL ACHIRILOAIEI', MIHAI MEDELEANU2*
1University Politehnica Timisoara, Mechanical Engineering Faculty, 6 Carol Telbisz, 300001, Timisoara, Romania

3University Politehnica Timisoara, Industrial Chemistry and Environmental Engineering Faculty, 6 Carol Telbisz Str.,300001,

Timisoara, Romania

Degradation and breakage of Aluminium Clad Steel Reinforced (ACSR) conductors leads to power outages that have catastrophic impact from an economic, social and national security point of view. Frictions, vibrations, corrosion, as well as other chemical compounds from the environment, can be the main source of the damages. Environment provides much of the time less restrictive conditions than those designed in the standards. In this respect, issues of optimization and development of current diagnostics and forecasting techniques personalized on geographic areas arise.
\end{abstract}

Keywords: pollutants, conductor, corrosion, wire

The conductors are the uninsulated metallic ropes, stretched freely between poles and fixed onto them by supporting elements, which are operating in urban and wild areas. Dedicated studies toward the increase of safety in the operation of aerial power lines became relevant when considering risk reduction. The high importance of electrical conductors coupled with the very high costs for repairs and replacements have imposed that the lifetime of power lines conductors to be between 50 and 80 years [1]. Frictions and vibrations created by the wind, corrosion caused by industrial pollution as well as other chemical compounds from the environment can be accounted as the main source of the damages. This is a major problem in evaluation the durability of electrical conductors, more so when experimental studies have highlighted the devastating role of combined action of contact and fatigue on the durability of aluminium $[2,10]$.

Technology takes over most aspects of contemporary life, consequently an increase in electricity consumption occurs. For this reason and together with more and more pressing concerns for reducing the invasive impact of human civilization on the environment, the main objective is identifying the degrading elements. Evaluation of the electrical conductors depends on many parameters and factors, such as time, current flow, temperature, chemical composition of ambient, etc. and the permanent variation of them $[12,13]$. Thereby it has been demonstrated that on a section although some common features meet, depending on the position in the section there are several specific situations $[3,4,8]$. In order to optimize maintenance strategies, there is reliability-based research, with the global trend that preventative maintenance is replaced by predictive maintenance $[5,6,10]$.

The environment and the dynamic operating regime change the properties of the conductors by developing the corrosion phenomena. It is encountered both in the case of aluminum wires as well in the steel wires with degradation of the galvanic layer. Aluminum corrosion involves the destruction of the aluminum oxide layer resulting from passivation by adsorption of anions. This chemical transformation of aluminium surface is followed by the direct attack of the metal [9]. G. Chen et al. [1] presents the results of special tests performed on the wires of a steel-aluminum conductor which was in operation for 25 years. The emphasis was put on determining the properties of wires in the clamping area of the conductor. Consequently, the wear adhesion of wire layers could be observed. In areas affected by contact there were found numerous cracks of modes I and II. Cracks open in mode I stimulate the production of aluminum oxide, which further accelerates the wear of the wire $[1,8]$.

\section{Experimental part}

Methods, materials and equipment

Laboratory tests have been performed to collect samples from electrical conductors used for the transport of electricity by ACSR airlines. The wires in this research are divided into: new wires - unused in the transport of energy and aged wires - in service for 42 years. The new wires were taken from a conductor produced by IPROEB Bistrita according to standard STAS 35/1999 and are part of the 450/75 steel-aluminum category, with the type and composition listed in Table 1. The aged wires were taken from the active conductors on the high voltage network, Porble de Fier-Arad from the Timisoara-Arad, to have climatic and environmental conditions present in west of the country. The two conductors are distinguished by the different appearance of the superficial coatings present on the aged conductor as shown in Figure 1.

The tests were performed using a scanning electron microscope model SE Quanta FEG 250 equipped with EDAX analyzer and Apollo SDD detector, using magnifications 120x, 200x and 400x.

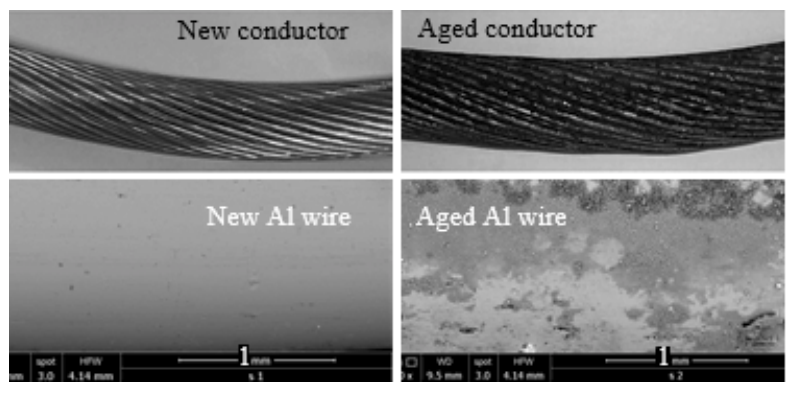

Fig. 1. New and aged conductor's surface aspect

\begin{tabular}{|l|l|l|l|l|l|l|l|l|l|}
\hline Type & Purity & Fe & Si & Cu & Mn & Zn & Ti & Cr & Others \\
\hline 1350 & $99.5 \%$ & 0.4 & 0.1 & 0.05 & 0.05 & 0.05 & 0.03 & 0.01 & 0.1 \\
\hline
\end{tabular}

Table 1

TYPE AND CHEMICAL COMPOSITION OF NEW ALUMINUM WIRES [7] 

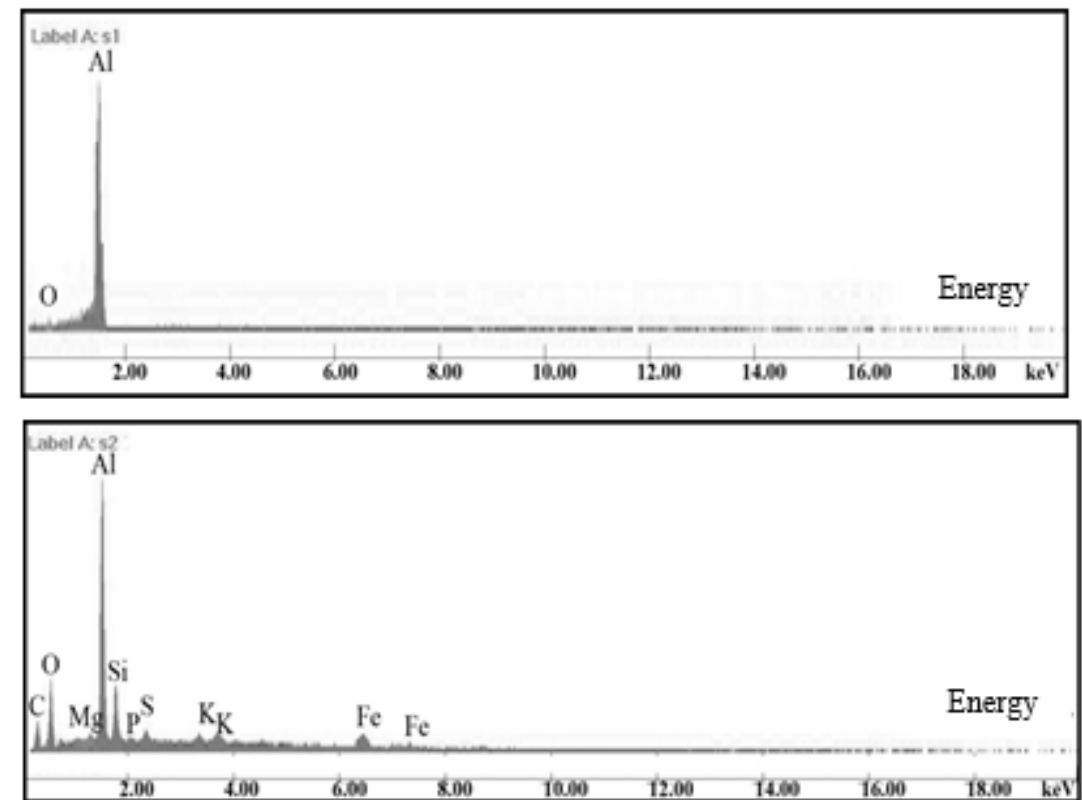

Fig. 2. X-ray characteristic spectrum for new wires

Fig. 3. X-ray characteristic spectrum for aged wires

$X$-ray detection with energy dispersion

New and aged conductors were used for the measurements, from which aluminum wires prepared at lengths required by the dimensions of the electron microscope. Considering their thermal conductivity, it was not necessary to load samples with absorbed electrons, and the images obtained were stable. In both new and aging conductors, wire surfaces have not been decontaminated to have a clear image of the appearance, shape and size of superficial particles, superficial defects, of lubricant layer and of surface topography. X-ray intensities have been measured by photon counting and general analytical precision is $\pm 2 \%$. The Figures 2 and 3 show the $X$-ray microanalysis of aluminum wires drawn from new and aged conductors where the characteristic peaks can be distinguished.

\section{Differential Thermal Analysis}

DSC (Differential Scanning Calorimetry) was used to observe the changes in material properties with temperature. The conductor samples, aged or not, were characterized by DSC, which allowed the study of heat absorption processes ( the amount of heat absorbed by the sample) as well as the determination of the melting enthalpy before and after aging. In the Figure 4 is depicted

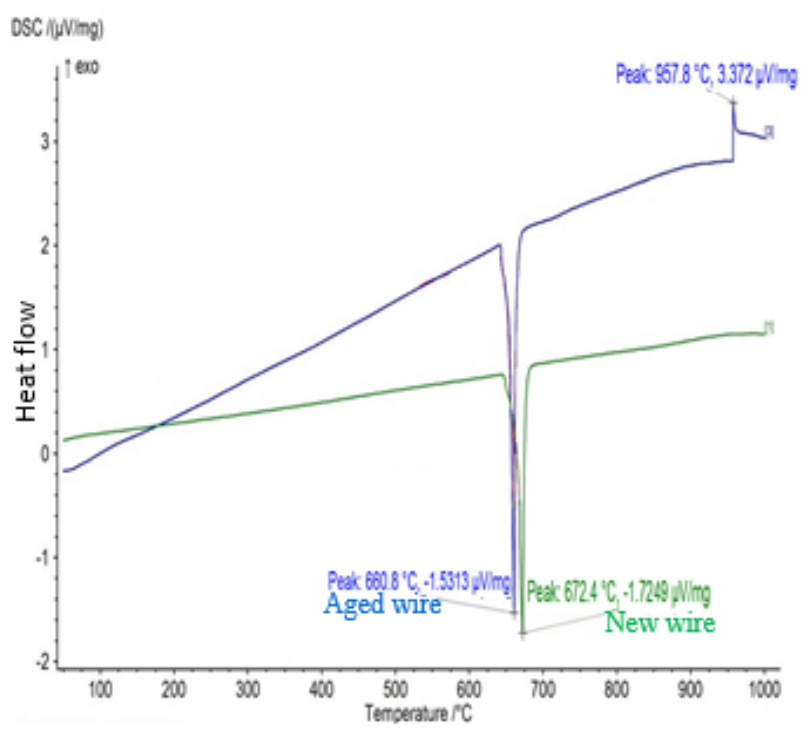

Fig. 4. DSC Thermogram for new and aged wires the thermogram obtained for new, unprotected wires, respectively, used in the transport of electricity, subject to the aging process.

\section{Results and discussions}

X-ray detection indicates a large difference between the two types of conductors. In addition to the two elements found on new wires, aged wires show other unusual elements, the proportion of which varies with the sampling position. Thus, some elements are specific to industrial areas, mainly agricultural areas and urban areas. There are also the following elements: carbon, magnesium, silicon, phosphorus, sulfur, potassium, iron, presumable as chlorides, nitrates, oxides, phosphates, carbonates and sulfates, concordant to agricultural area between Timisoara and Arad. A variation of the oxide layer is given by time so that, in the case of aged wire, a substantial increase in the peak characteristic to oxygen is observed.

The estimation of the lifetime of conductors exposed to current environmental conditions across Timisoara - Arad is possible applying the method average annual loss of torsional ductility vs. environmental corrosion index used by Havard D.G. [9] and the mechanical tests results acquired by Achiriloaiei D. [8]. Two important components

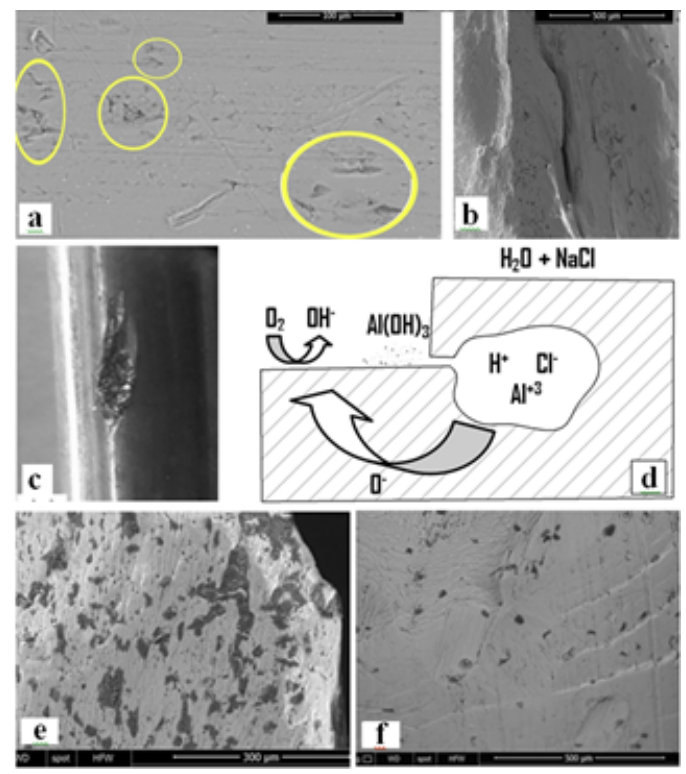

Fig. 5. Types of corrosion on aluminium wires 
are needed: the average yearly loss in ductility and the atmospheric corrosion index rating.

The decrease of ductility in this case is taken as a measure of conductor lifetimes and it was established based on the results obtained at tensile tests $(20 \%)$, bending tests $(5 \%)$, torsion tests (17\%), shear tests $(15 \%)$ [8]. Using different weighting factor of the above results, depending on the behavior of the conductor, a loss of ductility of the old conductor has been established at $17 \%$. Determination of atmospheric corrosion index was made using the corrosion index algorithm [9] applying the results obtained into X-ray detection. The local environmental corrosion index is 2,5 based on the methods used by Havard D.G [9].

In the case of aged aluminum wires, several types of corrosion have been encountered which are consistent with those described in the literature $[1,5,7,11]$ :

a.continuous corrosion - Figure $5 a$, occurs at the surface of the wire due to the modification of the $\mathrm{pH}$ from the environment given by the predominantchemical elements;

b.atmospheric corrosion - Figure 5b, occurs due to continuous exposure to air pollutants and varies from one geographic area to another;

C.corrosion in the material gaps - Figure 5b, 5d, develops in material defects or surface cracks. This is due to the presence of salt water entering these interstices where the phenomena of dislocation and dissipation of aluminum occur;

d.corrosion spots - Figure $5 e$, these appear as random stains on the surface of the wire, under normal humidity and temperature, in superficial material defects;

e.corrosion by friction - Figure $5 c$, a result of friction between wire surfaces and has the appearance of a black dot covered with dust. This is due to the contact pressure, after which the particles of dislocated material stick together, then break and stick again;

f.the fatigue corrosion - Figure $5 f$, occurs as cracks or superficial plastic deformations due to wire movements and tensions create areas where corrosion can develop.

The main difference between the two thermograms consists in the fact that the base line, determined by the heat flux absorbed by it in the elastic domain, is around $0.15 \mu \mathrm{V} / \mathrm{mg}$ for the new wire and $0.2 \mu \mathrm{V} / \mathrm{mg}$ and $-0.2 \mu \mathrm{V} /$ $\mathrm{mg}$, respectively on aged wire. The temperature at which the peak is obtained, corresponding to the viscoelastic flow region and the melting of the material, is quite different, $672^{\circ} \mathrm{C}$ with $-1.725 \mu \mathrm{V} / \mathrm{mg}$ and $661{ }^{\circ} \mathrm{C}$, respectively with $1.531 \mu \mathrm{V} / \mathrm{mg}$ and $663^{\circ} \mathrm{C}$ with $-0.476 \mu \mathrm{V} / \mathrm{mg}$.

\section{Conclusions}

The layers of corrosion products vary in thickness on the contact surfaces of the wires with the surrounding environment conditions but have low effects due to the aluminum's property of forming a layer of oxide, which increases its corrosion resistance. A variation is also observed in the case of geographic location changes compared to [9], depending on factors such as weather, wind direction, dust, precipitation, temperature, quantity and type of pollutants, as well as proximity to natural bodies of water which speed up the process.

The presence of atmospheric chemical compounds alters the behavior of conductors over time for similar types of stresses as shown by the results of the laboratory tests in the paper [8]. On the other hand, knowing that the exposure area is in an agricultural zone, one can expect the presence of chemical compounds on the electrical surface of conductors mainly from chemical fertilizers and the wind exposure.

There are significant variations in the aging wire thermograms due to the different content from the elements present on the material mass. With the content increase, the base line is lower at lower values and increased at high voltages, while the peak temperature is slightly lower but with a higher voltage difference $\mu \mathrm{V} / \mathrm{mg}$. More environmental data are required to determine the atmospheric corrosion of the site. Based on field measurements of corrosive materials, suspended particles and their concentrations in air, a corrosion index customized on areas, like those found in literature [5], may be developed according to predictive maintenance proposals.

Acknowledgement: The authors would particularly like to recognize the contributions of Institutul de Cercetãri pentru Energii Regenerabile -ICER Timisoara, for providing access to analytical and optical devices.

\section{References}

1.GUOHONG CHEN, XU WANG, JIAQING WANG, JUNJIAN LIU, TAO ZHANG, WENMING TANG, Damage investigation of the aged aluminium cable steel reinforced (ACSR) conductors in a highvoltage transmission line, Elsevier-Engineering Failure Analysis, Vol. 19, 2012, p. 13-21

2.MARTINSL.H.L., ROSSINO L.S., FILHO W.W.B., ARAUJ OJ .A., Detailed design of fretting fatigue apparatus and tests on 7050-T7451 Al alloy, Tribology - Materials Surfaces and Interfaces, Vol. 2, 2008, p. 39-49

3.KIM H.S., MALL S., Investigation into three-dimensional effects of finite contact width on fretting fatigue, Finite Element in Analysis and Design, Vol. 41, 2005, pp. 1140-1159

4.SUZANNE G., Power Line Conductors, a contribution to the analysis of their dynamic behaviour, Ph.D thesis, 2011

5.EPRI Transmission Line Reference Book: Wind Induced Conductor Motion, Electric Power Research Institute, Palo Alto, California, United States, 2006

6.RIZZO P., DI-SCALEA F.L., Monitoring steel strands via ultrasonic measurements, SPIE 2002, Vol. 4696, 2002, p.62-73

7. *** www.badgerwire.com.au, Datasheet aluminium 1350 aloy Badger Wire, 2017, p.1-2

8.ACHIRILOAIEI D., KUN L., NES C.S., DUMITRU I., Comparative study of mechanical properties of aluminium wires from new and used acsr conductors, Solid State Phenomena, Vol. 254, 2016, p.159163

9.HAVARD DG, BELLAMY G., BUCHAN P.G., Aged ACSR conductors. Part II: Prediction of remaining life, IEEE Trans Power Delivery, 1992, Vol. 7, p. 588-595

10. WILSON M., HURLEBAUS S., Power line monitoring, Proceedings of the American Control Conf., 2007, p. 231-235

11. DUMITRU I., CERNESCU A, Oboseala conductoarelor liniilor electrice aeriene, Ed. Academiei Romane, Bucuresti, 2017, p. 182-225 12. LINGVAY I., LINGVAY C., CIOGESCU 0., HOMAN C., Contrubutii la studiul si controlul degradarilor prin coroziune ale cablurilor electrice subterane, Rev.Chim. (Bucharest), 58, no. 1, 2007, p $44-46$

13. DUMITRESCU V., MORARU M., CAMENITA I., BRÂNZOI I. V. , ACHIOPESCU A., Cinetica coroziunii otelurilor în ape de zãcãmânt, Rev. Chim. (Bucharest), 59, no. 4, 2008, p 426-42.

Manuscript received: 4.12 .2018 